Proceedings

\title{
A New Light Aircraft and Its Design Method ${ }^{\dagger}$
}

\author{
Marius-Ion Ghițescu ${ }^{1, *}$, Marilena Ghițescu ${ }^{1}$ and Arina Modrea ${ }^{2, *}$ \\ 1 Department of Mechanical Engineering, Faculty of Mechanical Engineering, Transilvania University of \\ Brasov, 500036 Brasov, Romania; marilenaradu71@yahoo.com \\ 2 Department of Industrial Engineering and Management, Faculty of Engineering and Information \\ Technology, University of Medicine, Pharmacy, Sciences and Technology, George Emil Palade of \\ Târgu Mureș, 540142 Târgu Mureș, Romania \\ * Correspondence: marius.ghitescu@unitbv.ro or m_ghitescu@yahoo.com (M.-I.G.); \\ arina.modrea@umfst.ro (A.M.) \\ + Presented at the 14th International Conference on Interdisciplinarity in Engineering-INTER-ENG 2020, \\ Târgu Mureș, Romania, 8-9 October 2020.
}

Published: 22 January 2021

\begin{abstract}
The paper presents some aspects related to a new light aircraft that has as fields of use sports and leisure aviation. It also has a maximum capacity of two seats and a certain aerodynamic shape and which has on the wings mounted curved flaps for the flight board without hinges, as well as for gliding the plane in critical flight conditions or when it is necessary to save fuel. The paper presents and optimal design method of this new light aircraft.
\end{abstract}

Keywords: light aircraft; design method; optimal; symmetric geometry

\section{Introduction}

The activity of designing a product part uses knowledge acquired in the fields of mathematics, physics, strength of materials, technical drawing, study of metals, materials technology, tolerances and dimensional control, technology of machine construction.

Aircraft design is an information intensive engineering process full of evaluation and decision-making. Conceptual design phase, compared with the entire design process, consumes relatively less time and costs; however, many tasks should be carried out, and a lot of important decisions will have to be made during this period. It is estimated that as much as $80 \%$ of the life cycle costs of an aircraft is decided in the conceptual design and preliminary design phase [1-3].

The wing loading is the weight of the aircraft divided by the area of the reference (not exposed) wing. As with the thrust-to-weight ratio, the term "wing loading" normally refers to the takeoff wing loading but can also refer to combat and other flight conditions. Wing loading affects stall speed, climb rate, takeoff and landing distances and turn performance. The wing loading determines the design lift coefficient, and impacts drag through its effect upon wetted area and wing span. Wing loading has a strong effect upon sized aircraft takeoff gross weight. If the wing loading is reduced, the wing is larger. This may improve performance, but the additional drag and empty weight due to the larger wing will increase takeoff gross weight to perform the mission [4].

Aircraft sizing is the process of determining the takeoff gross weight and fuel weight required for an aircraft concept to perform its design mission.

It is known in the literature the light aircraft Extra $300 \mathrm{LT}$ at which the force load of the direction reaches $90 \mathrm{~kg}$ [5]. The Extra $300 \mathrm{LT}$ is a one- or two-seater acrobat aircraft produced by German manufacturer Extra Aircraft (Extra Flugzeugbau $\mathrm{GmbH}$, today Extra Flugzeugproduktions- und Vertriebs-GmbH). 
It is known the Zlin 142 light aircraft at which the load with forces reaches 200-250 N [6]. Zlin Z 142 is a single-engine aircraft with two seats for tourism and produced by Czechoslovak manufacturer Moravan Otrokovice (now ZLIN Aircraft Otrokovice, Czech Republic).

The new light aircraft has as its areas of use sports and recreational aviation with a maximum capacity of two seats [7].

The new light aircraft has a certain aerodynamic shape, symmetry geometry and good stability being made up of middle wings of rectangular shape and having in part an asymmetrical profile so that the profile rope forms an angle of incidence $\varphi_{\text {incidence }}=11^{\circ}$ with the direction of advance and a setting angle $\varphi_{\text {calaj }}=0^{\circ}$, from a front fuselage with a certain aerodynamic shape, a central fuselage with a certain aerodynamic shape and having 2 parts of different shapes in the cabin area, a rear fuselage with a certain aerodynamic shape, propeller helmet, ailerons, flaps, cabin, depth, drift, direction, stabilizer with profiled shapes [8-10].

\section{A New Light Aircraft and Optimal Design Method}

The technical problem of a new light aircraft is the improvement of the dynamic behavior of the light aircraft through the control mechanisms of the flaps and the constructive form of the aircraft, in the conditions of low manufacturing costs and in a favorable time for the aircraft, increasing the surface of the flaps, increasing the wingspan to allow the aircraft to operate in critical flight conditions or when fuel economy is required, enabling the aircraft to glide in these situations.

The design of the aircraft took into account the fact that the components of the aircraft must be simple to manufacture and assemble and accessible for repair.

When establishing the aerodynamic shape and the constructive dimensions of the light aircraft, the optimal design of the light aircraft was taken into account, as were the parameters that influence the aerodynamic shape of the fuselage and wing (Figures 1-5), as well as the flap and aileron installations and mechanisms mounted in these areas.
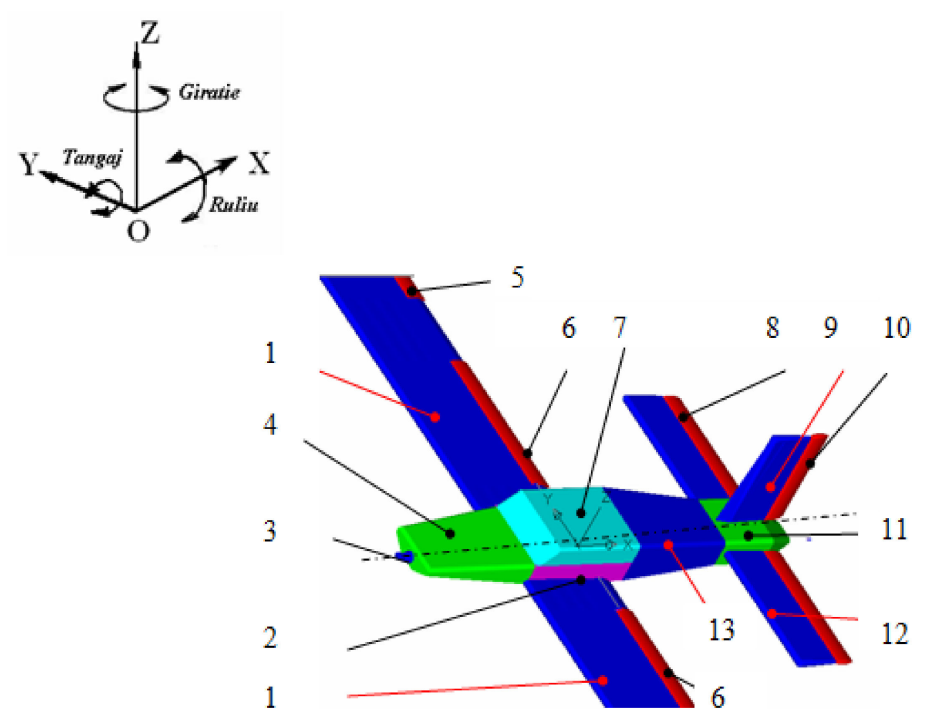

Figure 1. A new light aircraft. 1-the median wing of rectangular shape and having in part an asymmetrical profile so that the chord of the profile forms an angle of incidence with the direction of advance and an angle of choke of a certain length $L, 2$ - the central plane of the fuselage, 3-the helmet of the propeller, 4-front fuselage (bonnets), 5-aileron, 6-curved flaps or single flaps (one on each wing) located on the trailing edge without hinges (without axes of rotation on the wings), 7-the cab, 8-the depth (the moving part of the horizontal tail), 9-the drift (the fixed part of the vertical tail), 10-the direction (the moving part of the vertical plumage), 11-rear fuselage, 12-stabilizer (fixed part of the horizontal tail), 13—central fuselage (2nd part). 


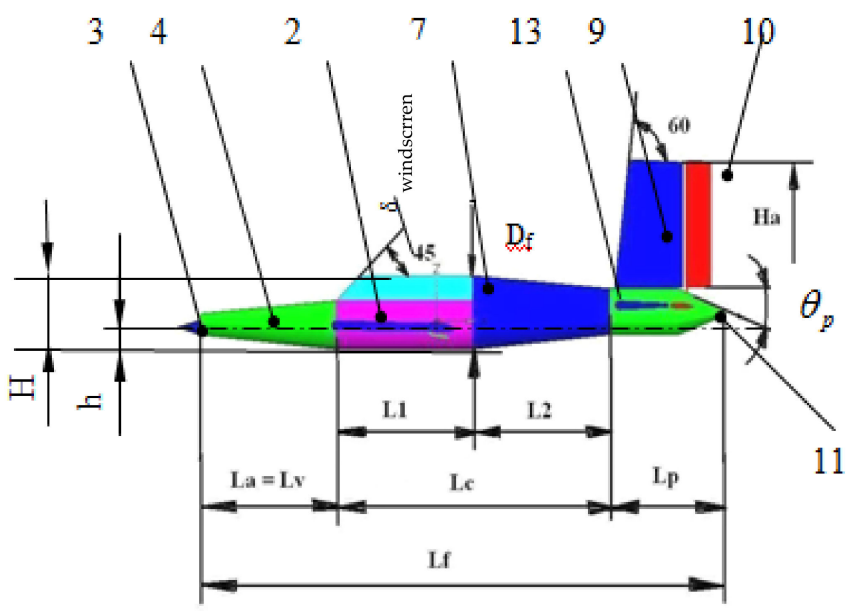

Figure 2. Lateral view of a new light aircraft.

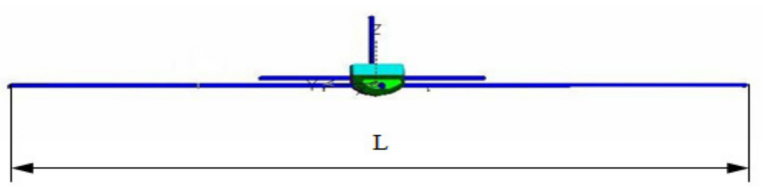

Figure 3. The frontal view of light aircraft.

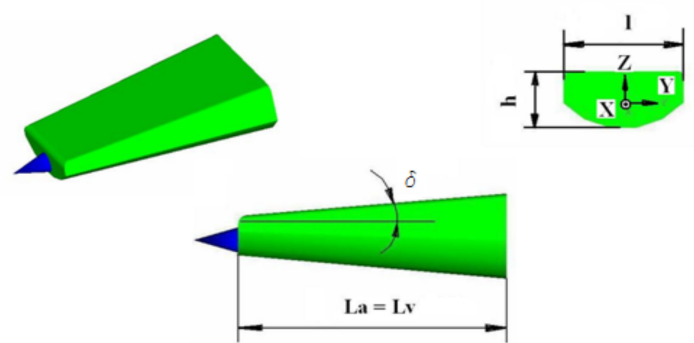

Figure 4. The first part of fuselage.
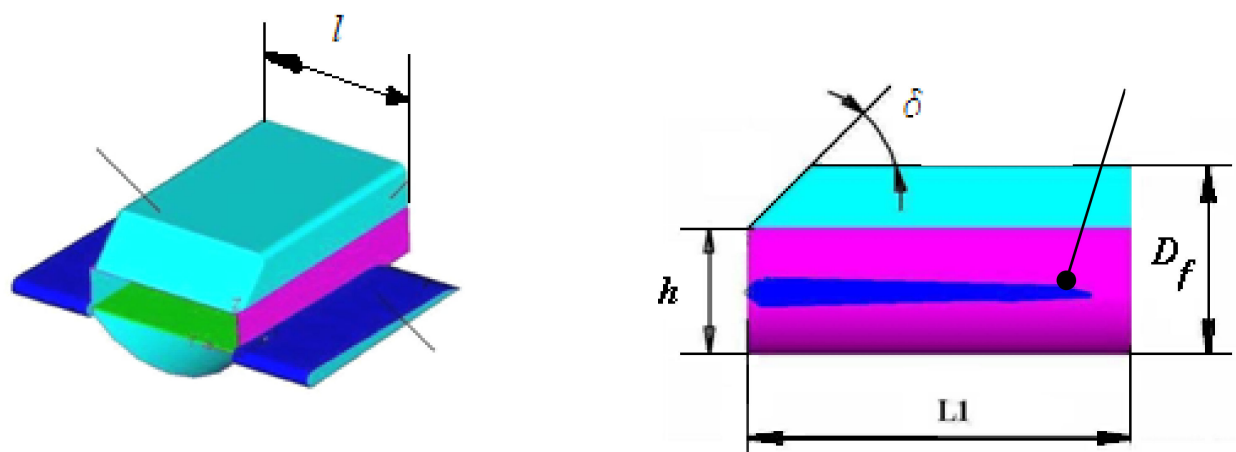

Figure 5. The central fuselage-Part 1.

The constructive solution of the new light aircraft consists of original components such as shape and dimensions to improve the aerodynamics of the aircraft and its stability, as follows: median wings, $L$-shaped, rectangular and having in part an asymmetrical profile so that the rope profile forms an angle with the forward direction, the central plane of the fuselage (Part 1 of the central fuselage), the propeller helmet, the front fuselage (hoods), ailerons and curves for the flight dashboard without 
hinges (one on each wing), the cabin housing the crew, the depth, the drift, the direction, the rear fuselage, the stabilizer and the second part of the central fuselage.

The advantages of the light aircraft are the following:

(a) The light aircraft has a simple and fast response structure, is safe and reliable and has good flight control and lifting performance and good stability.

(b) The aerodynamic shape of the airplane and the constructive shape of the flywheel control mechanism imply an increased service life.

(c) In order to increase the lift capacity of the aircraft, during take-off and landing, as well as during the flight, two curved flaps for the flight board without hinge (without axes of rotation with respect to the wings) were mounted on the wings, one on each wing.

(d) By increasing the length of the wings, an increased load-bearing surface was obtained, increasing the wingspan $L$ of the wings to a value greater than $(1.1 \ldots 1.3)$ times the length of the fuselage $L_{f}$, which led to an increase in the surface of the flaps, which allows the aircraft be able to glide in critical flight situations when the engine is no longer running or when needed for fuel economy, which allows the aircraft to easily behave like a glider.

Figure 1 shows in axonometric view the constructive solution of a new light aircraft, which consists of original components as a shape and dimensions to improve the aerodynamics of the aircraft and its stability, as follows: 1 -represents the median wing of rectangular shape and having in part an asymmetrical profile so that the chord of the profile forms an angle of incidence with the direction of advance and an angle of choke of a certain length L (2 pcs.), 2-the central plane of the fuselage, 3-the helmet of the propeller, 4-front fuselage (bonnets), 5-aileron ( 2 pcs., one on each wing), 6-curved flaps or single flaps (one on each wing) located on the trailing edge without hinges (without axes of rotation on the wings), 7-the cab, 8-the depth (the moving part of the horizontal tail), 9-the drift (the fixed part of the vertical tail), 10-the direction (the moving part of the vertical plumage), 11-rear fuselage, 12-stabilizer (fixed part of the horizontal tail), 13—central fuselage (2nd part) [7].

The aerodynamic shape and construction dimensions of this aircraft have been established by combining various geometric shapes for its components in order to obtain a good aerodynamic shape for the class of light aircraft and to fulfill the function of gliding when needed when fuel economy is needed or in critical flight conditions when the engine is no longer running.

The aerodynamic shape and constructive dimensions of the light aircraft shown in Figures 1-3 make this aircraft also fall into the category of glider, which means that the aircraft can glide as needed if the engine is no longer running or when the engine is stopped for fuel economy.

Figure 2 shows a side view of the light aircraft in which the important components and dimensions established in the design of the aircraft can be observed.

The aerodynamic shape of the light aircraft depends on the aerodynamics of the body systems of which the aircraft is composed. The fuselage being the supporting organ of the plane's transport load, its design starts from the interior partitioning necessary for the plane's mission.

The fuselage of a light aircraft consists of 3 large assemblies, namely, assembly 1 called the front fuselage 4 (front of the aircraft) in length, assembly 2 called the central fuselage which has 2 parts 1 and 2 (positions 2 and 13 lengths), and the last assembly being the rear fuselage 11 (from the tail of the plane) long.

The shape of the fuselage on light aircraft without special demands of an aerodynamic nature is imposed by technological considerations, manufacturing costs and useful volume.

The useful volume is the parameter that gives the available space inside where we can place the crew, luggage, equipment and fuel.

The payload depends on the carrying capacity of an aircraft which decreases with the reduction of the total length of the fuselage and the area of the maximum cross part.

A maximum useful aircraft volume means a lower than optimal aerodynamic shape. 
The fuselage of the aircraft is located in a stream of air and it produces lift (very low) but especially forward resistance: Lateral aerodynamic forces and aerodynamic moments act on it; its construction takes over all the demands of the other organs and elements of the aircraft.

In addition, in the fuselage are arranged spaces for crew, propulsion system, fuel tank, equipment, etc., which implies the existence of a well-defined volume. For the fuselage, an optimal solution must be found both from an aerodynamic and constructive point of view: with a front surface as small as possible to "close" a large volume, but at the same time, the shape of the body volume obtained, to be as aerodynamic as possible.

The front fuselage of a light aircraft, Figures 2 and 4, has an aerodynamic profiled shape, being made up at the bottom of a surface arranged under a circular arc on a length $L_{a}$, the straight side surfaces on the length $L_{a}=(1.2 \ldots 1.5)^{*} D_{f}$, and the part of above is a flat surface that is inclined at a certain angle $\delta=20^{\circ} \ldots 50^{\circ}$.

The maximum equivalent part $D_{f}=\mathrm{H}[\mathrm{mm}]$ for the center fuselage shall be determined according to the dimensions of the cab and of the installations which are contained in the fuselage.

For light aircraft with 2 adjacent seats, the area of the maximum rear fuselage part is recommended as $S_{f}=1.5 \ldots 1.7 \mathrm{~m}^{2}$. Determining the total length of the fuselage with the relation: $L_{f}=(6 \ldots 10)^{*} D_{f}$, where $L_{f} / D_{f}=l_{f}=6 \ldots 10$ represents the elongation of the fuselage.

At subsonic flight speeds, the pressure resistance in a laminar flow is relatively low compared to the frictional resistance, and there is no question of reducing it. As the forward resistance is mostly produced by the frictional resistance, it is recommended to use short (shorter) fuselages to reduce it.

The central fuselage has two aerodynamic parts (Figures 1, 2 and 5).

Part 1 of the central fuselage of a light aircraft has at the bottom a surface arranged under an arc of a circle on a length $L_{1}=L_{2}=(1.7 \ldots 2.0)^{*} D_{f}$, straight side surfaces; the top is straight, a front surface facing the cab inclined at a certain angle $\delta_{\text {windscreen }}=40 \ldots 55^{\circ}$, having in longitudinal part a profiled shape with dimensions $h=0.625^{*} D_{f}, L_{1}, D_{f}, H=D_{f}=(1.5 \ldots 1.7)^{*} h$ and an inclined front surface which is the windscreen inclined at a certain angle $\delta_{\text {windscreen }}=40 \ldots 55^{\circ}$ for optimum visibility, Figure 5 .

Part 2 of the central fuselage of a light aircraft (Figures 2 and 6) has a profiled aerodynamic shape having at the bottom a surface arranged under an arc of a circle on a length $L_{2}=L_{1}$ and inclined at an angle $\delta_{1}=\left(10^{\circ} \ldots 25^{\circ}\right)$, the straight side surfaces, and the top is a flat and inclined surface at a certain angle $\delta_{1}=\left(10^{\circ} \ldots 25^{\circ}\right)$, having in longitudinal part a frustoconical shape with large base $H=D_{f}$, length and angle of inclination of the side edges $\delta_{1}=\left(10^{\circ} \ldots 25^{\circ}\right)$.

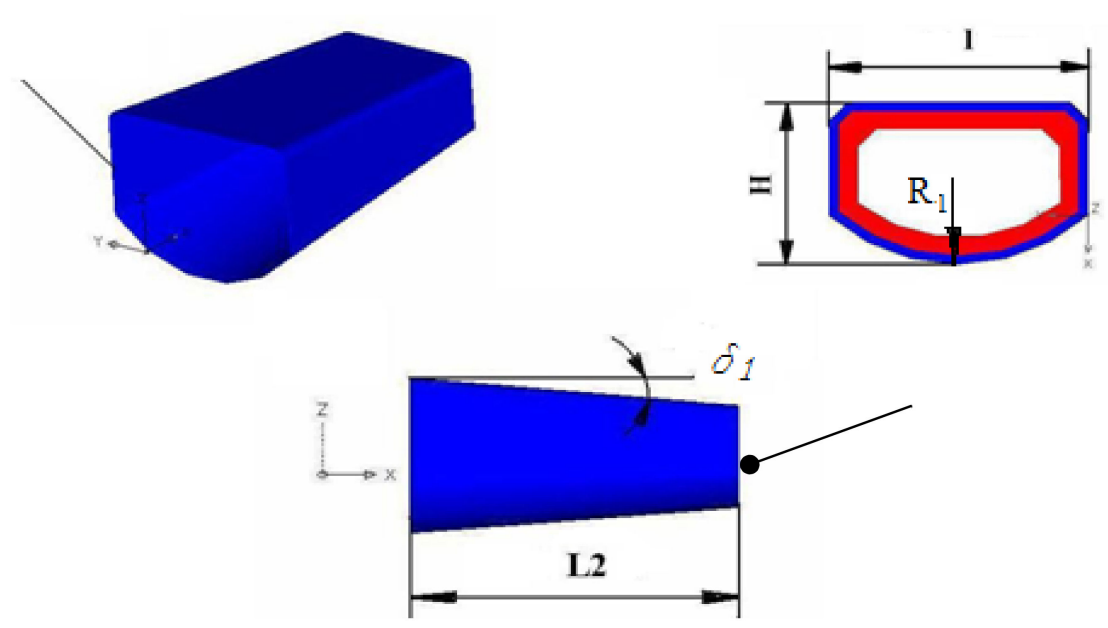

Figure 6. The central fuselage-Part 2.

The shape of the rear fuselage is shown in Figures 1 and 7 . The rear fuselage of a light aircraft has a profiled aerodynamic shape, being formed at the bottom of a surface arranged under an arc of a circle on a certain length $L_{p 1}=0.7^{*} L_{p}$; the left-right side surfaces are straight on a certain length $L_{p 1}=0.7^{*} L_{p}$, 
and the surfaces from the tail of the plane are inclined at a certain angle $\theta_{p}=20 \ldots 50^{\circ}$ on a length $L_{p}-L_{p 1}=0.3^{*} L_{p}$, where $L_{p}=(1.2 \ldots 2.5)^{*} D_{f}$.
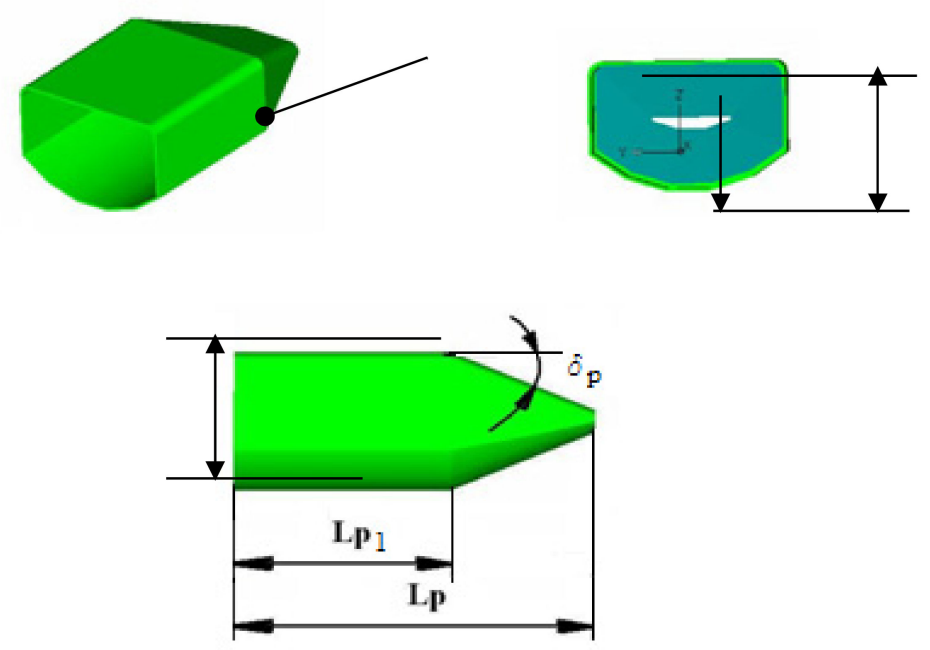

Figure 7. The rear fuselage.

The middle wing of a light aircraft (Figures 1-3) has a profiled aerodynamic shape, the wing having a rectangular shape and an asymmetrical profile in part so that the profile rope forms an angle of incidence $\varphi_{\text {incidence }}=11^{\circ}$ with the direction of advance and a right angle. $\varphi_{\text {chocking }}=0^{\circ}$, and the wingspan $L$ of the wing is greater than $(1.1 \ldots 1.3)$ times the length of the fuselage $L_{f}=(6 \ldots 10)^{*} D_{f}$, ( $D_{f}=H[\mathrm{~mm}]$ — the maximum equivalent part for the central fuselage, for a non-circular profile) to allow the aircraft to behave like a glider due to the length of the wings and the aerodynamic shape, to glide when needed for fuel economy or in critical flight situations when the engine is no longer running.

The middle wing is advantageous in terms of interaction with the fuselage.

Figure 3 shows a front view of the light aircraft and the wingspan $L$ of the wings.

When designing the fuselage of the aircraft, the operating conditions necessary for the fuselage were taken into account: maximum payload, access to all installations mounted in the fuselage, heating, ventilation, tightness, good visibility for the crew. The strength and rigidity of an aircraft are maximum at a minimum weight of the resistance structure.

The design of the aircraft took into account the fact that the components of the aircraft must be simple to manufacture and assemble and accessible for repair.

Increasing the length of the wings also increases the length of the flaps, which leads to increased lift during takeoff and landing of the aircraft slightly.

At subsonic flight speeds, a great influence on the aerodynamic characteristics has also the attack board of the wing profile, reason for which its sharp shape is avoided because it does not allow obtaining large lifting forces.

When the plane flies at relatively low speeds, the evolutions are made at high angles of incidence. The detachment of the boundary layer that begins with the increase of the angles of incidence is manifested with greater intensity in the area where the wing joins the fuselage. This detachment results in an increase in the forward resistance, a decrease in lift and a displacement of the center of pressure.

Upon landing, the pilot reduces engine traction and automatically reduces the lift. Volleyballs driven at negative downward angles ensure an increase in lift at this critical time, behaving like an aerodynamic brake.

At take-off, the traction of the engine increases successively, and the flaps as hypersuspension devices ensure an increase of the load-bearing force and the reduction of the take-off distance. 
The optimal design method of the light aircraft is to establish the calculation steps that define the parameters of the fuselage and the wing and the aerodynamic shape of this aircraft depending on the maximum equivalent part $D_{f}$ in the cabin area where the crew sits, the value of the magnitude $L=(1.1 \ldots 1.3)^{*} L_{f}$, of the installations that are mounted in these areas.

Figure 8 shows the logic diagram underlying the optimal design of the aerodynamic shape of a light aircraft with the steps to be followed.

1. Determining the maximum equivalent part $D_{f}=H[\mathrm{~mm}]$ for the center fuselage for a non-circular profile.

2. Determining the total length of the fuselage with the relation: $L_{f}=(6 \ldots 10)^{*} D_{f}$, where $L_{f} / D_{f}=l_{f}=$ 6 ... 10, represents the elongation of the fuselage.

3. The establishment of the ratio between the sum of the lengths of the previous fuselage $L_{a}$ and the length $L_{1}$ of Part 1 of the central fuselage compared to the total length $L_{f}$ of the is calculated with the relation:

$$
\left(L_{a}+L_{1}\right) / L_{f}=0.2 \ldots 0.3
$$

where $L_{a}[\mathrm{~mm}]$ represents the length of the front fuselage, $L_{1}[\mathrm{~mm}]$-the length of Part 1 of the central fuselage (cabin area), $L_{f}[\mathrm{~mm}]$ - the total length of the fuselage.

4. The determination of the elongation of the front fuselage is calculated with the relation:

$$
L_{a} / D_{f}=1.2 \ldots 1.5 \text { or } L_{a}=(1.2 \ldots 1.5)^{*} D_{f}[\mathrm{~mm}] .
$$

5. Setting the Peak Angle for the front fuselage $\delta=20^{\circ} \ldots 50^{\circ}$. It was adopted $\delta=30^{\circ}$.

6. Determining the Length $L_{1}, L_{2}$ of the two parts of the central fuselage, the total length $L_{c}$ of the central fuselage, and the angle of inclination $\delta_{1}$ of the edges with the relations:

$$
\begin{gathered}
L_{1}=L_{2}=(1.7 \ldots 2.0) * D_{f}[\mathrm{~mm}], \delta_{1}=10^{\circ} \ldots 25^{\circ} \\
L_{c}=L_{1}+L_{2}=2 * L_{1}=2 * L_{2}=(3.4 \ldots 4.0) * D_{f}[\mathrm{~mm}]
\end{gathered}
$$

where $L_{1}[\mathrm{~mm}]$-length of Part 1 of the central fuselage (in the cab area), $L_{2}[\mathrm{~mm}]$ - the length of Part 2 of the central fuselage, $L_{c}$ 一the total length of the central fuselage, and $\delta_{1}$-the angle of inclination of the side edges.

7. The establishment of the lateral surface of the fuselage is approximated with the relation:

$$
S_{\text {lat }}=K \pi D_{f} L_{f}=\left[0.734+14.5 \times 10^{-3} \times(6 \ldots 10)\right] \pi D_{f} L_{f},\left[\mathrm{~mm}^{2}\right]
$$

where $K=0.734+14.5 \times 10^{-3} \times(6 \ldots 10)$.

8. Determining the angle of the rear fuselage $\theta_{p}=20 \ldots 50^{\circ}$. It is adopted $\theta_{p}=30^{\circ}$.

9. Determining the length of the rear fuselage $L_{p}=(1.2 \ldots 2.5) * D_{f}[\mathrm{~mm}]$.

10. Determining the inclination of the windshield (dome). $\delta_{\text {windscreen }}=40 \ldots 55^{\circ}, \delta_{\text {windscreen }}=45^{\circ}$ was adopted for better visibility.

11. The determination of the height $h[\mathrm{~mm}]$ is determined with the following relation:

$$
h=0.625 * D_{f} .
$$

12. The determination of the width $l[\mathrm{~mm}]$ of the cabin is determined with the following relation:

$$
l=1.0625 * D_{f} .
$$

13. The determination of the height $H[\mathrm{~mm}]$ is determined by the following relation:

$$
H=D_{f}=(1.5 \ldots 1.7) * h
$$


$D_{f}=1.6^{*} h$ was adopted.

14. The determination of the height $H_{a}[\mathrm{~mm}]$ of the direction is determined by the following relation:

$$
H_{a}=(1.2 \ldots 1.3) * D_{f}
$$

$H_{a}=1.235^{*} D_{f}$ was adopted.

15. Determination of the wingspan (distance between the extreme ends of the wings) $\mathrm{L}[\mathrm{mm}]$, the angle of incidence $\varphi_{\text {incidence }}\left[{ }^{\circ}\right]$ and the angle of offset $\varphi_{\text {chocking }}\left[{ }^{\circ}\right], L=(1.1 \ldots 1.3)^{*} D_{f}$. We adopted $L=1.15^{*} L_{f}, \varphi_{\text {incidence }}=11^{\circ}$ and $\varphi_{\text {chocking }}=0^{\circ}$.

16. CAD modeling and optimization of the aerodynamic shape of the light aircraft.

17. Simulation of the plane with Adams software.

18. Practical execution and testing of light aircraft.

The optimal method of designing the light aircraft is to go through the following steps:

When the aircraft is operating lightly, the two flaps on the wings bend (rotate downwards) symmetrically, only at negative angles.

During the flight of the aircraft, the two identical ailerons on the wings brace anti-symmetrically to each other at positive and negative angles and generate the roll motion.

In the current stage of industrial development in conditions of high competition in the aero industry market, each manufacturer must develop its own strategy.

It seeks to reduce as much as possible the time interval between the conception (design) of an installation and its execution.

For this purpose, the use of the computer in all stages of design and production is a basic requirement. Thus, it is necessary:

- Real-time simulation of the dynamic behavior for these aircraft command and control installations.

- Virtual prototype optimization.

Aircraft must comply with special design and execution conditions. These apply to all subassemblies and components.

Computer modeling and virtual prototyping are valuable tools for creation.

The materials used for its execution also have an influence on the aerodynamics of the light aircraft and its minimum weight. The main components of the light aircraft (for example, fuselage, wings, tailings, throttle controls, ailerons) can be made of various materials (e.g., duralumin or composite materials) so as to obtain good aerodynamics and a minimum weight of plane.

By using composite materials, the weight of the aircraft is considerably reduced, the aerodynamics is improved, and its mechanical strength and reliability are increased. 


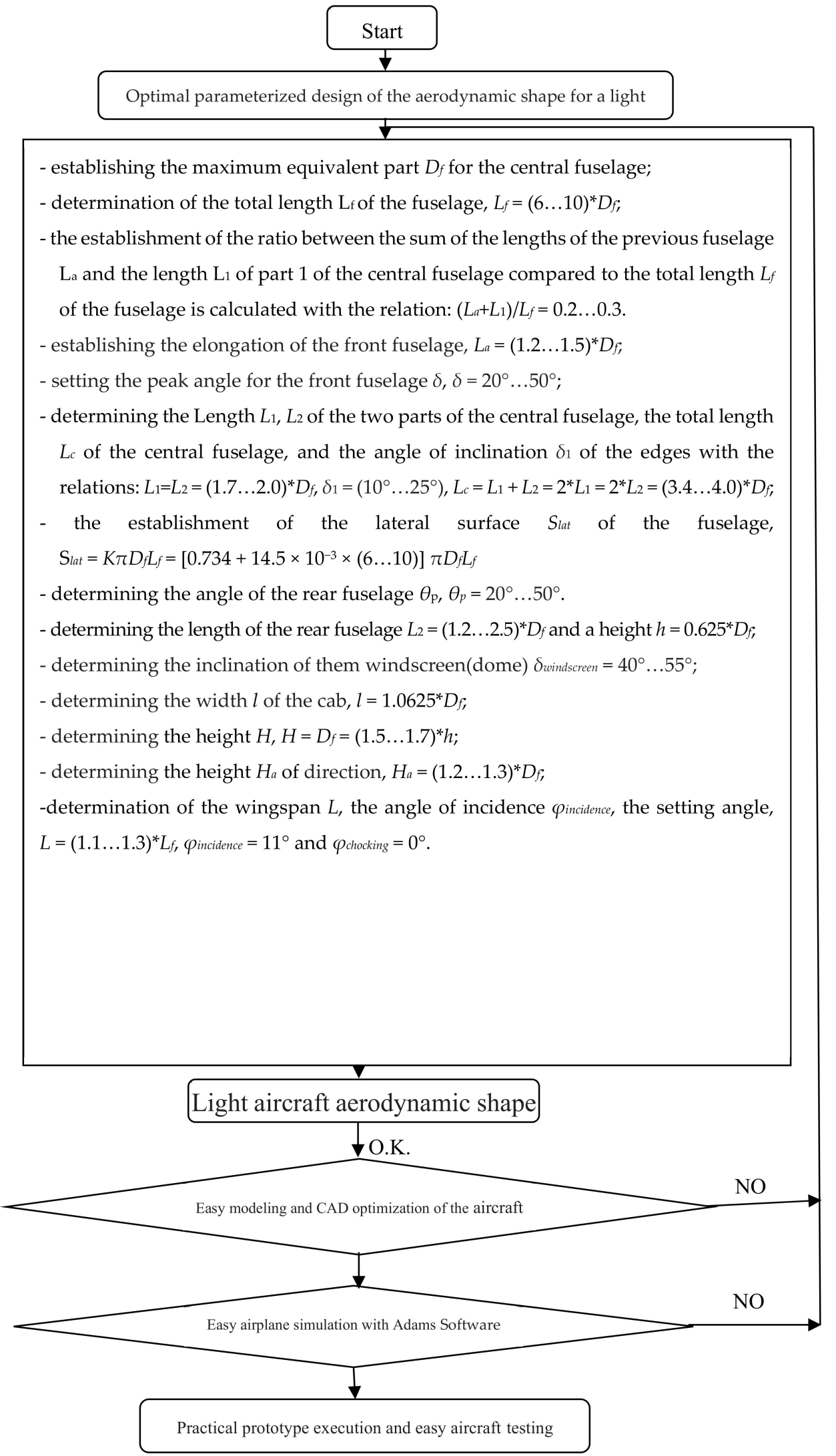

Figure 8. The logic diagram of optimal design method of light aircraft. 


\section{Conclusions}

The process of aircraft conceptual design includes numerous statistical estimations, analytical predictions and numerical optimizations. However, the product of aircraft design is a drawing. While the analytical tasks are vitally important, the designer must remember that these tasks serve only to influence the drawing, for it is the drawing alone that ultimately will be used to fabricate the aircraft.

All of the analysis efforts to date were performed to guide the designer in the layout of the initial drawing. Once that is completed, a detailed analysis can be conducted to resize the aircraft and determine its actual performance.

This detailed analysis is time-consuming and costly, so it is essential that the initial drawing be credible. Otherwise, substantial effort will be wasted upon analyzing an unrealistic aircraft.

The design layout process generally begins with a number of conceptual sketches.

A good sketch will show the overall aerodynamic concept and indicate the locations of the major internal components. Once the design has been analyzed, optimized, and redrawn for a number of iterations of the conceptual design process, a more detailed drawing can be prepared.

The crew station will affect the conceptual design primarily in the vision requirements.

Requirements for unobstructed outside vision for the pilot can determine both the location of the cockpit and the fuselage shape in the vicinity of the cockpit. The pilot must be able to see the runway while on final approach, so the nose of the aircraft must slope away from the pilot's eye at some specified angle. While this may produce greater drag than a more streamlined nose, the need for safety overrides drag considerations. Similarly, the need for over-side vision may prevent locating the cockpit directly above the wing.

The vision angle looking upward is also important. Light Aircraft should have unobstructed vision forwards and upwards to at least 20 deg above the horizon.

By increasing the length of the wings, an increased load-bearing surface was obtained, increasing the wingspan $L$ of the wings to a value greater than $(1.1 \ldots 1.3)$ times the length of the fuselage $L_{f}$, which led to an increase in the surface of the flaps, which allows the aircraft be able to glide in critical flight situations when the engine is no longer running or when needed for fuel economy, which allows the aircraft to easily behave like a glider.

Computer modeling and virtual prototyping are valuable tools for creation.

By applying a virtual prototyping algorithm, we can shorten the distance between the creation and execution of the physical prototype. By increasing the length of the wing and the wingspan, the surface of the flaps is obtained. By increasing the surface of the shutters, the load is increased. By increasing the load and by increasing the steering angles, the take-off and landing of the aircraft is done in a shorter time and over a shorter distance.

\section{Patents}

The content of this paper is the subject of a patent application entitled "Light aircraft and flap control mechanism".

Author Contributions: Conceptualization, M.-I.G.; methodology, M.-I.G., M.G. and A.M.; software, M.-I.G. and M.G.; validation, M.-I.G.; formal analysis, M.-I.G., M.G.; investigation, M.-I.G.; resources, M.-I.G.; data curation, M.-I.G.; writing—original draft preparation, M.G.; writing—review and editing, M.G. and M.-I.G.; visualization, M.G.; supervision, M.-I.G. and A.M. All authors have read and agreed to the published version of the manuscript.

\section{References}

1. Postelnicu, A. Aerodynamic Profiles; Transilvania University of Brasov: Brasov, Romania, 1997; pp. 27-54.

2. Roskam, J. Airplane Design, Part I. Preliminary Sizing of Airplanes; University of Kansas: Lawrence, KS, USA, 1985; pp. 44-100.

3. Raymer, D. Aircraft Design: A Conceptual Approach; Air Force Institute of Technology: Wright-Patterson Air Force Base, OH, USA, 1989; pp. 3-603. 
4. Tomažič, T.; Matko, D.; Karba, R. Theoretical and practical approach to full-scale aircraft modelling. IFAC Proc. Vol. 2009, 42, 1223-1228. [CrossRef]

5. Maintenance Manual Extra 300 LT Aircraft. Available online: https://www.extraaircraft.com/docs/techmanuals/MM300LT/300LT_MM_20150612.pdf (accessed on 22 July 2020).

6. Maintenance Manual Zlin 142 Aircraft. Available online: http://aerodromclinceni.ro/wp-content/uploads/ 2012/07/Man-de-zbor-Z142-rev8-lb-eng.pdf (accessed on 22 July 2020).

7. Ghitescu, I.-M.; Vlase, S.; Ghitescu, M. Light Aircraft and Flap Control Mechanism. Patent Application No. CBI A/00223, 27 April 2020.

8. Florescu, N. Aerodynamics of the Airplane; Scrisul Romanesc Publishing House: Craiova, Romania, 1984; pp. 34-94.

9. Gavrila, J. Aircraft Aerodynamics; Dacia Foundation: Brasov, Romania, 2000; pp. 30-90.

10. Grosu, I. Aircraft Calculation and Construction; Didactic and Pedagogical Publishing House: Bucharest, Romania, 1965; pp. 18-80.

Publisher's Note: MDPI stays neutral with regard to jurisdictional claims in published maps and institutional affiliations.

(C) 2021 by the authors. Licensee MDPI, Basel, Switzerland. This article is an open access article distributed under the terms and conditions of the Creative Commons Attribution (CC BY) license (http://creativecommons.org/licenses/by/4.0/). 